\title{
The Impact of New Media Events on College Students' Thoughts and Their Countermeasures
}

\author{
Zhixue Wang \\ Higher Education Research Institute, Jilin Agricultural University, Changchun,China \\ 23512277@qq.com
}

Keywords: College students; New media events; Platform; Network literacy; Values

\begin{abstract}
The emergence, development and dissemination of new media events have a great impact on College Students' ideology, to a certain extent; it influences college students' values and social psychology, which brings new challenges to the ideological education of college students. In front of the new media event, whether students can face it objectively and rationally, and scientifically analyze social problems in a positive way, which is worth thinking deeply.
\end{abstract}

\section{Introduction}

The Connotation of New Media Events. The study of media events (media events) in communication studies was originated in 1950s. in our country, the formulation is not much, most of the scholars of our country are called "media event" ", Some foreign scholars through the work of the system, the full rang to state media events and research media events and the environment, the relationship between public opinion and the connotation of media events, Some foreign scholars through the work of the system, the full range of media events and research media events and the environment, the relationship between public opinion and the connotation of media events, American press critic ,Walter Lippmann in 1922 published book "public opinion". Communications founder Wilbur Schramm in 1949 published the "mass communication" and the 1973 publication of "Introduction to communication" (Men, and Messages Media: Look at Human Communication A). Communication scientist, Daniel Boorstin published the book in 1961: "the image of America pseudo-event guide"; Daniel. Dai Yang and Elihu Katz in 2000 the book "media events of history live" and so on. Scholars define "media events" from different perspectives and paradigms: The medium is a platform for spreading "false" and "distorting" events or news in our life; The media event is a deliberate arrangement of news or changes in the real news or events, with "not true, not false" characteristics; Media events are "false facts", "false environment"; media events are the major events of the national TV live broadcast.

Domestic scholars have a lot of controversy on the relationship between the media and the new media events, Many scholars believe that the new media event is the traditional media events through the media and other new media, but also researchers will be defined as the new media event network hot events or network public opinion". Some scholars have defined the connotation of the new media event is narrow, the new media event is simply regarded as the "new media" event, has become a very narrow sense of the concept of the operation. The new media event emphasizes more on a single, simple event under the influence of new media such as the Internet, through the rapid spread of public opinion platform into a high degree of attention, strong influence of social news events.

The Concept of New Media Events. The "new" is a relatively "old" character, newspapers and radio have been the new media platform for the relatively old medium, Elihu Katz refers that Satellite TV transmission is relatively new in tern of newspaper media, and the current new media mainly refers to the mode of transmission based on the mobile network. I believe that the so-called new media events, is a non-governmental organizations or individuals dominated by the Internet and mobile media dissemination of interactive events of social events. 


\section{Organization of the Text}

The Impact of New Media Events on College Students' Ideology. Published in early 2015 thirty-fifth China Internet network development situation statistics report, the data show that China's 649 million Internet users, college students accounted for $28.9 \%$ of Internet users. College students' major Internet device is a mobile phone, and the usage rate is $63.1 \%$. The popularity of new media in Colleges and universities and the audience is self-evident. The network has gradually become an important platform for college students' political participation, access to information, public opinion interaction; each one airs his own views. Contemporary college students are concerned about state affairs and social development through new media, so in recent years, the "new media events emerge in an endless stream" on the ideological impact should not be overlooked. From the pros and cons of two aspects to impact the college students, ideological educators in Colleges and universities should pay more attention to the impact of new media events on College Students' ideology.

The Positive Impact of New Media Events on College Students' Ideology. Because new media events spread fast and wide, college Students' curiosity is strong, the frequent occurrence of new media events become the focus of attention of College students, and they are good at capturing the social problems in the event of new media, at the same time the new media events also affect college students, prompting them to spread positive energy. In "Wenchuan earthquake" "Wenzhou accident" and "defend the Diaoyu Islands" "Earth Hour" and "micro-blog" crackdown "love transfer" and "Xiamen PX" event, the students through forwarding and comments, through the network platform, participate in the development of new media events. They are concerned about the people's livelihood, but also concerned about the state affairs; they are concerned about the public figures, but also concerned about the grassroots; They express their opinions, views and opinions on the new media events through the network, most of the times, the university student is the major of the new media event and also the promoters, enhancing the enthusiasm of college students to participate in social life and reflect on the social phenomenon, and stimulating the university student's sense of justice, the sense of responsibility, the sense of mission, the patriotism, the compassion and the national sentiment.

The Impact of New Media Events on College Students' Values. University stage is the formation period of College Students' Outlook on life, values and world outlook. In the face of all kinds of information and complex news events on the Internet, college students are vulnerable to the impact of negative news and false information, shaking the ground, losing yourself; Do not know how to face the power, status, money, interpersonal relationships, moral humanity, etc.. In the face of display of wealth by "white Formica and rich handsome" two rich generation and the two generation, " Guo Meimei incident", "Yao Jia Xin event", "my father is Li Gang" and other negative new media events, misleading college students, and impacting the traditional moral concepts and behavior of College students. The new media events in the money worship, hedonism, extreme individualism, nationalism, pragmatism, utilitarianism, nihilism, pluralistic values and social thoughts, all constantly impact, change the university student's thought and the life style. One-sided exaggerate the contradictions of the new media events.

The Impact of New Media Events on the Social Psychology of College Students. The social mentality is that people hold the more general social attitudes, emotional experience and intention, and other psychological states for themselves, the surrounding environment and the reality of society, Also refers to a general psychological state of people in the face of major events and emergencies. The psychological state are showed by college students in the face of a major or sudden "new media event", including mental health, life satisfaction, psychological and emotional, event recognition, self-esteem and support, fairness and other psychological characteristics and behavior patterns.

On the one hand, college students are active in thinking, good at expressing and questioning; On the other hand, their psychology is not mature enough, easy to blindly, curry favour by claptrap. As plasticizer incident "Hangzhou racing" "Deng Yujiao" "little moon" "Shishou incident" and "Fu Lei political event officials suspended according to" APEC "blue" in recent years, the negative impact 
caused by the spread of exaggerated and misleading media events, it is difficult to adhere to their own ideas, resulting in confusion, vulnerable to extreme emotional impact. Due to the new media platform with a low threshold and strong concealment, students in the platform can see the release of discontent, an ulterior motive, extreme anger, hatred and even attack negative remarks, their psychology is also generally affected, more sense of lack of social trust and a sense of fairness, by the impact of social dark emotions to become cynical. Once in the study life encountered difficulties and setbacks, will complain, the accumulation of a large number of negative and negative emotions, forming a huge psychological pressure, to influence f College Students' social mentality health.

\section{New Media Event Coping Strategies for College Students}

Promoting College Students' Network Literacy. The quantity network information is big with a wide dissemination scope and the quick speed, at the same time, every time all the new media events occurred on the network, the network has become the cradle of the new media events, distributing center, and against the ground. These events relate to all aspects of social life, with help from the difficulties and disasters in, the generosity of commonweal and support action, and from micro-blog to ask perseverance benign interaction of political corruption network. The "positive energy" in the new media event is to be cast and confirmed by the college students. Meanwhile, some confusing people, disrupting social order, malicious speculation, wanton abuse, advocating the Western peaceful evolution thought, vulgar information overflow etc. The new media events, under the impetus of the "black hand" "waves". After these events are used and spread, lead students authenticity and blind faith. These "negative energy" produces a huge "tornado" effect and impact, challenging resolution ability of College students.

Ideological education workers in Colleges and universities should strengthen the network quality of College students, to help and guide students and improve the ability to distinguish right from wrong, using scientific, objective and rational analysis of the new media events, to eliminate the interference factors, to distinguish the authenticity of the information. Learning to find and discover new media events for their own and social significance and influence, there is a choice to accept and deal with all kinds of information in the event of judgment.

Education to guide college students to strengthen the network of legal constraints, moral norms and self-control, to treat science, backward, reactionary new media events, and students should improve their ability to grasp the information of the new media. College students take the initiative to achieve guidance, not blindly, not biased and not blindly, not to spread, and improve the ability of new media event information dissemination, dissemination, discrimination and comment, to prevent his impulse to become false events of new media followers and promoters, and take on the social responsibility of College students.

To Guide College Students to Establish a Correct Outlook on Life, Values and World Outlook and Cultivate a Harmonious Social Mentality. The university period is the formation and development period of young people's outlook on life, values and world outlook, in the face of all the new media event, the educators in Colleges and universities should guide students to correctly understand the society. Rational view of the problem of refraction amplification with the political, economic and social fields in the period of social transition, in time through the situation policy report, the network forum, experts to explain the general concern of the new media events and analysis of College students, analyze the authority and rationality, to guide college students to correctly understand the new media events.

Education guides college students to maintain a healthy, sunny, upward social attitude towards a series of social problems such as the gap between the rich and the poor, the problem of corruption, food safety, environmental pollution, and moral ethics and so on. College students should not be affected by the bad phenomenon of new media events and decadent ideas, should actively respond to the difficulties encountered in the growth and setbacks, firm ideals and beliefs and go out of 
confusion and confusion, in the face of problems to analyze problems, reflect and solve problems, what's more, actively and gradually cultivate appreciation of their own, treat themselves, treat others in a calm mood and healthy mentality.

Build New Media Education Platform, through the New Media Events to Carry out Ideological Education. The new media events through new media publishing and dissemination, college students are the important participants in the new media platform, the emergence of new media network platform, to provide students more diversified perspectives. New media events caused college students more bold in network participation and discussion, comment. This is an urgent need to regulate the network behavior of college students, to strengthen the network of moral education, guide college students to civilized access the Internet, civilized speech, preventing the false information and bad public opinion from the emotion and wrong behavior; For the distortion of the new media events, it is necessary to clarify the right and wrong, give the truth and facts and reduce the negative spread of new media events.

Universities should give full play to the educational role of the new media platform, to play a positive energy, in the new media events embedded the socialist core values education, social morality, professional ethics, family virtues and personal moral education, format moral self-discipline, Zonta goodness, comity tolerant morality; To guide college students to accurately understand the situation and participate in the society, in the details of the new media event, the sense of perception, the experience of the sublime, the promotion of identity, cultivate the social responsibility of young students, national consciousness, humanistic feelings, scientific spirit, good sentiments, good will.

Colleges and universities should be in the interests of College Student, such as the selection of student cadres, students will change, organizational development, Scholarship Selection and other new media events in the campus, avoiding the campus common events caused by information asymmetry into a new media event, timely release of information through the network platform, to clarify the truth, to distinguish the right and wrong, relieve antagonism, and timely resolve of college students and the school of Mao Dun, to prevent the media events of the media distortion and spread.

\section{References}

[1] [America] Daniel Dai Yang, Elihu Katz. Media events -- history live [M]. Ma Zhengqi. Beijing: Beijing Broadcasting Institute press, 2002

[2] [America] LiPuman. Public opinion study [M] Yan Kewen, Jiang Hongyi. Shanghai: Shanghai Century Publishing House, 2006

[3] Xiao Yuefeng, Li juita. The influence of network hot spot on University Students' thought and behavior [J]Higher education forum, 2011 (08)

[4] Deng Jing. Discuss on the impact and reconstruction of the social morality of the network hot events [J]. China Press, 2012 (04).

[5] Zhao Guihua. "New media events" and media public [J]. news lovers, 2010 (05).

[6] Zhou Jianhui. Basic rules and characteristics of network hot spot events [J].Young reporter, $2011(11)$.

[7] Du Lei, Zhao Na. College students' attitude towards Internet events and their guidance [J].Journal of Southwest Agricultural University (SOCIAL SCIENCE EDITION), 2012 (04) 